\title{
A enfermagem em Portugal aos 40 anos do Serviço Nacional de Saúde
}

\author{
Nursing in Portugal in the National Health Service at 40
}

Inês Fronteira (https://orcid.org/0000-0003-1406-4585) ${ }^{1}$

Élvio Henriques Jesus (https://orcid.org/0000-0002-8407-9240) ${ }^{2}$

Gilles Dussault (https://orcid.org/0000-0002-5976-3454) ${ }^{1}$

${ }^{1}$ Instituto de Higiene e Medicina Tropical, Universidade Nova de

Lisboa. R. da Junqueira 100. 1349-008 Lisboa Portugal. ifronteira@ihmt.unl.pt ${ }^{2}$ Instituto de Ciências da Saúde, Universidade Católica Portuguesa. Lisboa Portugal.

\begin{abstract}
We describe the development of nursing in Portugal since the creation of the National Health Service (SNS) in 1979, focusing on staff numbers, education, work conditions, career, and professional organization. We used the literature on the evolution of the Portuguese health sector and statistical data from the Nursing Council and the SNS. The number of nurses grew by 233\% in the last 40 years, but the nurse/physician ratio only increased from 1.15 to 1.4. Most work in hospitals, despite repeated political commitments to expand primary health care. In the SNS, 55\% are public servants, and the others are employed through private law contracts. The basic nursing course is currently offered in 20 public and 16 private institutions. In 2019, the career structure was revised and now comprises three categories: nurse, specialist nurse, nurse manager. Nurses remain moderately satisfied despite complaints about working conditions, remuneration, and lack of career progress. Nurses' role barely changed over the years, and the Medical Association is resisting to its expansion.
\end{abstract}

Key words Nursing, Portugal, Evolution of the profession, Education, Working conditions
Resumo Retratamos a evolução da enfermagem em Portugal desde a criação do Serviço Nacional de Saúde (SNS) em 1979, focando sobre os efetivos, a formação, as condições de trabalho, a carreira, e a organização profissional. Utilizamos a literatura sobre a evolução do sector da saúde em Portugal, e fontes de dados estatísticos da Ordem dos Enfermeiros e do SNS. Nos últimos 40 anos, o número de enfermeiros aumentou de $233 \%$, mas o rácio enfermeiro/médico só passou de 1.15 para 1.4. A maioria exerce funções nos hospitais, apesar dos repetidos compromissos politicos a favor da expansão dos cuidados de saúde primários. No SNS, $55 \%$ são funcionários públicos com contrato por tempo indeterminado; os outros detêm um contrato individual de trabalho de direito privado. O curso de licenciatura em enfermagem é oferecido em 20 escolas do sector público e 16 do sector privado. Em 2019, a carreira de enfermagem foi revista em 3 categorias: enfermeiro, enfermeiro especialista e enfermeiro gestor. Apesar de queixas em relação as condições de trabalho, a remuneração e ao progresso na carreira, os enfermeiros continuam moderadamente satisfeitos. O papel do enfermeiro, mudou pouco ao longo dos anos e há resistência por parte da Ordem dos Médicos à sua expansão.

Palavras-chave Enfermagem, Portugal, Evolução da profissão, Educação, Condições de trabalho 


\section{Introdução}

O sistema de saúde português evoluiu profundamente desde a criação, em 1979, do Serviço Nacional de Saúde (SNS) através do qual o Estado assegurou o direito constitucional à proteção $\mathrm{da}$ saúde dos cidadãos portugueses ${ }^{1}$. Nos últimos 40 anos, o SNS não se conformou plenamente a esse projeto inicial. Atualmente, o sistema de saúde português caracteriza-se pela coexistência e sobreposição de três sistemas: o SNS, os subsistemas de saúde (planos de seguro para grupos profissionais específicos, como, por exemplo, os funcionários públicos) e os seguros privados de saúde 2 . Mas é sobretudo ao SNS que se atribuem os ganhos em saúde conquistados por Portugal $^{3}$, o que contribuiu para que o estado de saúde dos portugueses esteja ao nível dos melhores da Europa ${ }^{4}$.

Neste artigo, começamos por apresentar uma breve síntese da evolução nas últimas 4 décadas do sector da saúde, retratando, simultaneamente, a evolução da enfermagem - focando sucessivamente sobre os efetivos, sua composição e sua distribuição, a formação, a organização profissional, a carreira e as condições de trabalho, as tarefas, e as relações com o Estado. Por último, discutimos os maiores desafios atuais e algumas perspetivas futuras.

\section{Método}

Realizámos uma revisão narrativa da literatura. Foram pesquisados na base de dados Diário da República Digital os diplomas publicados desde 15 de Setembro de 1979, data de constituição do SNS Português à presente data para identificar $\mathrm{e}$ descrever as principais políticas relacionadas quer com o sistema de saúde, quer com a profissão de enfermagem. Utilizámos, igualmente, literatura publicada e cinzenta sobre a evolução da enfermagem em Portugal, buscando os sites das instituições ligadas à enfermagem (e.g. Ordem dos Enfermeiros) e sites oficiais do Governo Português (e.g., Ministério da Saúde e suas instituições, Ministério da Ciência, Tecnologia e Ensino Superior). Os dados estatísticos foram obtidos a partir das fontes oficiais que se encontram devidamente referenciadas no texto, tendo sido utilizado o horizonte temporal adequado a ilustrar a ideia subjacente.

\section{Resultados}

\section{Da criação do SNS até a atualidade: evolução do sistema de saúde português}

Em 1976, a Constituição da República Portuguesa consagrou a saúde como um direito universal ${ }^{5}$, efetivado, em 1979, com a criação do SNS universal e gratuito, através do qual o Estado garante $o$ acesso de todos os cidadãos, independentemente da sua condição económica, a cuidados integrados de saúde, i.e. promoção e vigilância da saúde, prevenção da doença, diagnóstico e tratamento e reabilitação médica e social ${ }^{1}$. É também nesta data que se dá a Regionalização da Saúde em ambas as Regiões Autónomas de Portugal, e são criados os Serviços Regionais de Saúde. O diploma de criação do SNS estipulou que a política de recursos humanos para o SNS ficaria centralizada e, em 1982, este passa a ter autonomia administrativa e financeira, com um orçamento próprio ${ }^{6}$. É em 1983 e 1984 que se inicia a expansão do SNS através da consolidação dos cuidados de saúde primários $^{7,8}$. Entre 1985 e 1994, verificou-se, na saúde, um predomínio da ideologia de mercado, através do incentivo da competição entre prestadores públicos e privados de modo a obter ganhos de eficiência. Por outro lado, durante este período assistiu-se a um retraimento do Estado prestador através da implementação e políticas de priorização de serviços ${ }^{9}$. A primeira Lei de Bases da Saúde foi publicada em 1990 e nela se encontra reflexo das características deste período: regionalização da administração dos serviços, privatização de sectores de prestação e cuidados e de financiamento de cuidados e articulação de cuidados, através de unidades de saúde ${ }^{10}$.

Paralelamente, e em termos de política de recursos humanos, se, aquando da constituição do SNS se encarava a imprescindibilidade da dedicação exclusiva dos seus profissionais, é neste período que se assiste ao progressivo abandono da exclusividade, nomeadamente, dos médicos, com o intuito de estimular a atratividade do exercício no setor público. Tal tendência culmina com a publicação da própria Lei de Bases da saúde que veio permitir que os profissionais quadros do SNS pudessem exercer atividade privada salvaguardando quaisquer encargos adicionais para o SNS ${ }^{11}$. Foi, também, neste período que foi confirmada a necessidade de encontrar novas formas de divisão do trabalho por universos mais extensos, compreensivos e menos estanques. 
Entre 1995 e 2001, houve um movimento de afastamento do Estado em relação ao sector da saúde ${ }^{9}$. Foi criado um regime remuneratório baseado no desempenho, dirigido especificamente aos médicos dos cuidados de saúde primários ${ }^{12}$. Em 1997 são criadas as agências de contratualização ao nível das Administrações Regionais de Saúde tendo em vista separar as funções do Estado de prestador e de financiador.

Entre 2002 e 2010 assistiram-se a importantes reformas a nível hospitar e dos cuidados primários. Foi definido um novo modelo de gestão dos hospitais em que estes passaram a adotar regras de direito privado na gestão de recursos humanos e na contratação de bens e de serviços enquanto o estatuto e a gestão se mantinham públicos ${ }^{9}$. Tal levou a que fosse possível celebrar contratos individuais de trabalho com os profissionais de saúde e, desta forma, flexibilizar as relações laborais. Se, por um lado, esta medida permitiu aumentar a competitividade entre instituições do SNS ou reter mais profissionais, por outro introduziu entropia no conjunto da força de trabalho, com "remunerações diferentes para trabalhos iguais". É também neste período que, para os hospitais, surgem as primeiras parcerias público-privadas das quais subsistem, até hoje, 4 hospitais e sobre as quais ainda não foi atingido consenso ideológico, facto que se revelou o principal ponto de discórdia entre os partidos políticos na recente discussão sobre uma nova Lei de Bases de Saúde, entretanto promulgada ${ }^{13}$. A criação das Unidades de Saúde Familiar em 2007, como uma forma de organizar e prestar cuidados de saúde primários, constituiu uma inovação radical, num contexto tradicionalmente centralizador, que mudou significativamente o acesso aos cuidados primários (Quadro 1).

O período que se seguiu (de 2011 a 2014) foi dominado pela crise financeira e pela adoção de trinta e quatro medidas com o intuito de conter a despesa no sector da saúde, incluídas no Memorando de Entendimento assinado entre Portugal e as três instituições financeiras responsáveis pelo plano de regaste financeiro do país. Estas medidas resultaram, entre outras, numa diminuição dos salários dos profissionais de saúde, com o aumento da carga semanal de trabalho para a grande maioria em cerca de $14 \%$ e o congelamento das progressões e promoções. Também a nível do recrutamento se verificou uma diminuição significativa ${ }^{14}$. Entre 2011 e 2014, a força de trabalho no sector da saúde diminuiu de 122.580 efetivos para 116.884 , respectivamente ${ }^{15}$.
Nos cuidados primários a lista de utentes por médico de família aumentou de 1.500 para 1.900 , contribuindo para o aumento da carga de trabalho dos médicos, mas também, dos enfermeiros.

Durante este período, verificou-se um aumento da emigração dos profissionais de saúde, em particular dos enfermeiros. Neste último caso, enquanto que, em 2010, se estima que cerca de 500 tivessem emigrado, em 2011 o número duplicou para 1.000 e em 2012, 2013 e 2014 para 2.000 e voltou a aproximadamente 1.000 nos 4 anos seguintes. Durante este período, os enfermeiros emigraram principalmente para Inglaterra que registou a entrada de 781 enfermeiros portugueses em 2012 e de 1.211 em 2013. A perspetiva de encontrar trabalho, melhores condições de progressão, valorização profissional e remuneração foram os principais motivos que conduziram à emigração destes profissionais ${ }^{16}$.

Em 2015, o início de um novo ciclo legislativo marcou uma mudança radical na ideologia socioeconómica do país, coadjuvada por um ténue crescimento económico dos grandes países da União Europeia. Uma nova era de otimismo veio contribuir para uma lenta reversão na área da saúde: desde 2015 que a despesa publica em saúde tem aumentado, incluindo a remuneração dos trabalhadores da saúde, por via da redução do horário de trabalho semanal e descongelamento das progressões. Também durante esta legislatura se assistiu a um retomar da reforma dos cuidados primários através da criação de mais USF, da ampliação da cobertura de médico de família e de novas modalidades de contratualização, na forma de carteiras de serviços, entre outras. A nível dos hospitais, e tendo em vista a devolução progressiva da autonomia, foram selecionadas 10 instituições, com base em indicadores de eficiência, tendo em vista o incentivo a uma maior autonomia, incluindo a gestão dos recursos humanos ${ }^{9}$. No entanto, a contratação de pessoal mantém-se centralizada no Ministério da Saúde. Ainda neste último período, a carreira de enfermagem foi revista e a especialização em enfermagem valoriza$\mathrm{da}$, ainda que sujeita a quotas no que diz respeito à ocupação de postos de trabalho. O ano de 2019 foi ainda marcado pela discussão de uma nova Lei de Bases da saúde, promulgada em Agosto e que retomou o exercício em dedicação plena dos profissionais de saúde. Denominador comum às diferentes fases de evolução do SNS e do sistema de saúde português nos últimos 40 anos foi a inexistência de uma visão estratégica orientadora do desenvolvimento da força de trabalho em saú- 
Quadro 1. As Unidades de Saúde Familiar (USF): um modo inovador de acesso aos cuidados primários.

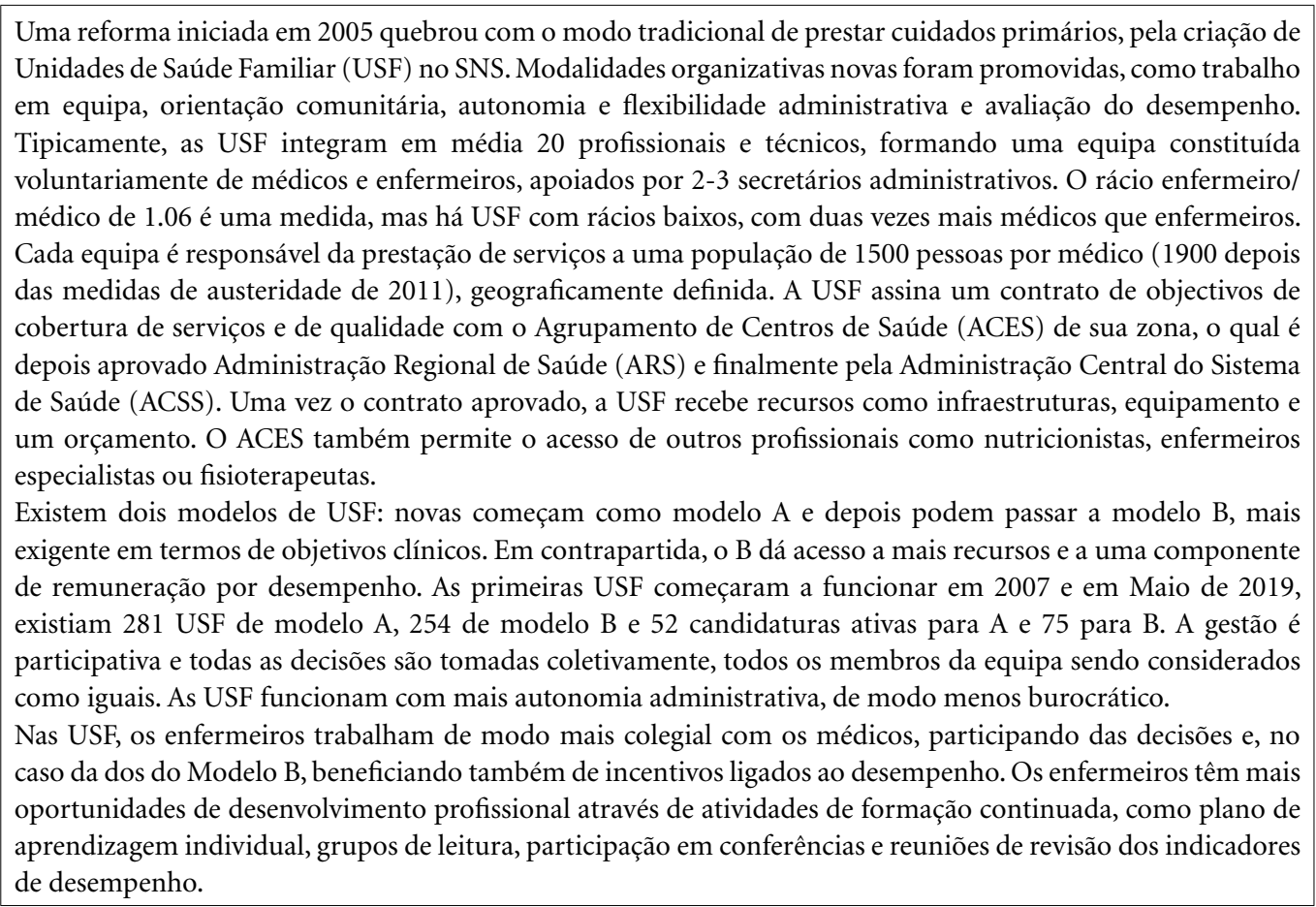

Fonte: Biscaia e Heleno ${ }^{17}$, Lapão e Pisco ${ }^{18}$.

$\mathrm{de}^{12,19}$ ainda que os primeiros exercícios de planeamento estratégico em saúde orientados para obtenção de ganhos em saúde ${ }^{20}$, tenham ocorrido em 1998 e se perpetuado até hoje.

\section{A enfermagem portuguesa em números}

O estabelecimento do SNS em 1979 criou a necessidade de mais profissionais de saúde. Em 1980, havia em Portugal 19.327 médicos e 22.144 enfermeiros. Nos últimos 40 anos, a população portuguesa cresceu $19,6 \%$, o que foi acompanhado por um crescimento de $178 \%$ (53.657) no número de médicos e de 233\% (73.650) no de enfermeiros.

Se, em 1980, existiam 505 habitantes por médico e 441 habitantes por enfermeiro; em 2018 o rácio era de 191 e 139, respetivamente. Também o número de enfermeiro para médico aumentou de 1.15 para 1.4 , embora permaneça abaixo da média dos países da União Europeia. Atualmente, os enfermeiros representam cerca de um terço do total dos trabalhadores do SNS com 43.312 efetivos, sendo esta força de trabalho maioritariamente feminina e jovem ${ }^{15}$.

Cerca de 70\% dos enfermeiros do SNS encontram-se na Região de Lisboa e Vale do Tejo (34\%) e na Região Norte (35\%) sendo que a grande maioria (79\%) exerce funções nos hospitais, apesar dos repetidos compromissos políticos a favor da expansão dos cuidados de saúde primários ${ }^{15}$.

A informação acerca da distribuição dos profissionais de saúde, nomeadamente médicos e enfermeiros, no sector privado é escassa. De um modo geral, os enfermeiros do sector privado são mais mal pagos que aqueles do sector público sendo que a carreira e as regressas de progressão são também diferentes.

\section{Educação}

O período de criação e expansão do SNS, entre 1974 e 1984, foi marcado por um aumento da procura do curso de enfermagem ${ }^{21}$, que passou a ser reconhecido como curso superior de curta-duração. Durante esta fase, foi criada, no SNS, uma carreira única de enfermagem com cinco categorias (de entre as quais a de enfermeiro especialista) aplicável às três áreas de atuação - prestação de cuidados, administração e docência. Pretendia-se garantir a prestação de melhores cuidados de enfermagem, maior aproveitamento dos recursos humanos existentes e eficiência dos serviços e maior realização e progressão profissio- 
nais. Foi durante este período que se criaram escolas pós-básicas, no Norte, Centro e Sul do país de modo a responder à necessidade de formação adicional, incluindo especializada, destes profissionais. O curso de enfermagem passou a corresponder o grau de bacharel. A formação de enfermagem é integrada no ensino politécnico, entre 1984 e 1995, o que impede a criação de cursos de licenciatura em enfermagem nas universidades, mesmo naquelas onde são já ministrados cursos de doutoramento e mestrado em enfermagem.

É no final da década de 90 que se dá a transição das escolas de enfermagem para a tutela exclusiva do Ministério da Educação e a reorganização da rede das escolas, com a sua integração em unidades mais amplas (institutos politécnicos, institutos politécnicos de saúde ou universidades) e é criada a figura da escola superior de saúde. São ainda criadas duas novas escolas superiores de saúde com o objetivo de alargar a oferta formativa a todos os distritos do país.

Desde 1999 que os enfermeiros têm uma formação de base de 4 anos que lhes confere o grau de licenciado em enfermagem ( $1^{\circ}$ ciclo de Bolonha). A passagem do curso de enfermagem a licenciatura permitiu o acesso "direto" aos graus de mestre ou de doutor, sem ser necessária uma licenciatura noutra área do conhecimento, como acontecia até à data. Em Janeiro de 2019, o curso de licenciatura em enfermagem, de 240 ECTS, correspondendo a 8 semestres lectivos, era oferecido em 20 Escolas Superiores de Enfermagem ou Escolas Superiores de Saúde do sector público e 16 do sector privado. São condições para aceder a esse curso a conclusão do $12^{\circ}$ ano de escolaridade e o cumprimento de pré-requisitos (e.g., exames nacionais) que variam de acordo com a instituição de ensino. A formação especializada em enfermagem se faz através da frequência do Curso de Pós-Licenciatura em Enfermagem (CPLE). No entanto, esta formação não confere grau académico. Algumas instituições de ensino, numa tentativa de ultrapassar este constrangimento, desenvolveram cursos de mestrado em enfermagem, alguns de denominação geral ou de denominação idêntica à das áreas de especialização. Os alunos que assim o desejem, fazem uma dupla matrícula, inscrevendo-se, simultaneamente no curso de mestrado e no CPLE. No final aqueles que completarem também a componente não letiva do mestrado, ficam habilitados com o grau de especialista, conferido pela Ordem dos Enfermeiros e com o título de Mestre, conferido pela instituição de ensino. O número de vagas para cada especialidade, assim como o tipo de especialidade ofereci- da são determinados pelas respetivas instituições de ensino.

Em 2018-19, um total de 1.381 vagas, acessíveis a enfermeiros com o mínimo de dois anos de experiência profissional, estavam disponíveis nas seguintes especialidades: reabilitação (402), saúde infantil e pediátrica (192), médico-cirúrgica (195), saúde comunitária (237), saúde mental e psiquiatria (195), e saúde materna e obstétrica (160). A especialidade de saúde comunitária compreende, ainda, duas áreas de subespecialização: enfermagem de saúde pública e enfermagem de saúde familiar. A especialidade de enfermagem médico-cirúrgica compreende 4 áreas de "subespecialização": cuidados intensivos, cuidados paliativos, cuidados perioperatórios e situação crónica (Quadro 2).

Em 2017, a Ordem dos Enfermeiros regulamentou áreas de competência acrescida em enfermagem definidas como conhecimentos, habilidades e atitudes que permitem o exercício profissional a um nível de progressiva complexidade, nos diversos domínios de intervenção do enfermeiro e ao desenvolvimento técnico-científico da profissão $o^{22}$ (p. 23636). Existem dois tipos de competências acrescidas - diferenciadas e avançadas. As primeiras acrescentam-se às competências do enfermeiro de cuidados gerais e ao enfermeiro especialista, enquanto as segundas apenas se acrescentam às competências do enfermeiro especialista. As competências acrescidas são reconhecidas pela Ordem dos Enfermeiros; independentemente do tipo de competências acrescida, a certificação é individual e averbada na cédula profissional. Atualmente, estão definidas quatro competências acrescidas diferenciadas: enfermagem do trabalho, supervisão clínica, emergência extra-hospitalar e estomaterapia; e quatro competências acrescidas avançadas: gestão, supervisão clínica e estomaterapia e psicoterapia.

\section{Condições de trabalho}

Atualmente, no SNS, os enfermeiros podem ser funcionários públicos ou deter um contrato individual de trabalho (direito privado). A maioria $(55 \%)$ é funcionário público com contrato por tempo indeterminado. O recrutamento de enfermeiros encontra-se centralizado e ocorre por concurso público. Em 2019, e após um longo processo negocial, a carreira de enfermagem foi revista definindo-se como pluricategorial com 3 categorias: enfermeiro, enfermeiro especialista e enfermeiro gestor ${ }^{23}$. Em termos de remuneração e benefícios, o salário de base de um enfermeiro 
Quadro 2. O reconhecimento da especialidade de enfermagem em saúde familiar.

Com a criação das USF, surgiu a questão do reconhecimento do caracter especifico da enfermagem nos cuidados
primários. Foram anos de debate antes do reconhecimento, pelo Decreto-Lei no $118 / 2014$, de 5 de agosto da
figura de "enfermeiro de família" como integrante das equipas de saúde familiar. O mesmo decreto-lei previa
experiências de inclusão de tais enfermeiros em 30 USF. Já em 2010, a Ordem dos Enfermeiros tinha proposto
uma definição das responsabilidades e tarefas do enfermeiro de família e algumas escolas de enfermagem
começaram a oferecer programas de especialização nesse campo. Todavia, por falta de consenso entre a Ordem,
os sindicatos e o Ministério da Saúde sobre o conteúdo do trabalho do enfermeiro de família, até 2017, esses
projetos-pilotos não haviam iniciado.
A Ordem só reconheceu a especialidade de enfermagem de saúde familiar como área de subespecialização da
saúde comunitária em 2018 .

Fonte: Simões et al. ${ }^{2}$.

é de 1.201,48 euros mensais antes dos impostos, subindo para $1.407,45$ euros na categoria de enfermeiro especialista e para 2.334,30 euros na categoria de enfermeiro gestor. A progressão na carreira encontra-se sujeita a cotas e é feita com base num sistema de atribuição de pontos.

No sector privado, a carreira de enfermagem encontra-se estruturada de forma diferente sendo que as remunerações são, em regra, mais baixas que no sector público, nomeadamente à entrada e os vínculos mais precários. Em média, um enfermeiro do sector privado pode esperar auferir um pouco mais de 1.015 euros mensais antes de impostos (www.sep.org.pt/files/uploads/2019/08/sep_14082019_bte.pdf). De uma forma geral, a remuneração dos enfermeiros, à semelhança do que acontece com os outros profissionais de saúde do SNS é percecionada como baixa e referida como um dos motivos para procura de trabalho fora do país. Nas USF de Modelo $\mathrm{B}$, os enfermeiros, para além do salário base, recebem ainda incentivos que estão indexados ao desempenho da unidade.

É difícil caracterizar os níveis de satisfação dos enfermeiros. Há dados, como o número de dias de greve (conhecidos) e das saídas para o sector privado e para o estrangeiro (estimadas) que sugerem níveis baixos. Há poucos estudos científicos disponíveis sobre o tema, salvo algumas teses académicas e outros trabalhos cobrindo pequenas amostras de profissionais. Esses estudos tendem a concluir sobre a existência de elevados níveis de insatisfação com as condições de trabalho, a remuneração e a progressão na careira. (http://www.rn4cast.eu/\#), replicado em Portugal, é o que apresenta uma imagem mais detalhada e mais rigorosa do ponto de vista científico, tanto pela amostra como pela utilização de questionários validados. Trata-se de um estudo quantitativo, observacional, transversal e analítico, no qual, entre novembro de 2017 e maio de 2018, participaram 5.075 enfermeiros de todas as regiões e contextos de prestação de cuidados de Portugal. A distribuição de respostas completas ao questionário está de acordo com os dados dos enfermeiros inscritos na Ordem dos Enfermeiros. A colheita de dados foi efectuada através do questionário RN4Cast, em suporte electrónico, divulgado, entre outros, através da comunicação organizacional da Ordem dos Enfermeiros, da Universidade Católica Portuguesa (UCP), página do estudo e redes sociais. Foram convidados a participar todos os enfermeiros que exerciam a profissão em Portugal e que dedicavam a maior parte do tempo à prestação directa de cuidados, independentemente do contexto. A participação foi voluntária e anónima. No que se refere às escalas do ambiente de prática, burnout e engagement, foram utilizadas as versões já traduzidas, validadas e aferidas para Portugal, cujos autores faziam parte da equipa de investigação. O Quadro 3 apresenta os principais resultados desse estudo.

\section{Organização da profissão}

Quem pretende exercer como enfermeiro em Portugal tem de se registar na Ordem dos Enfermeiros (OE) que verifica a possessão das qualificações exigidas para ter acesso ao mercado de trabalho, nomeadamente uma formação numa instituição reconhecida. A Ordem dos Enfermeiros foi criada em 1998 como Associação de Direito Público na qual o Estado passou a delegar os poderes de regulamentação e fiscalização do exercício profissional. Por natureza a Ordem é a organização que tem o maior número de membros. Existem, ainda, sindicatos (Associação Sindical Portuguesa dos Enfermeiros; Sindicato dos Enfermeiros Portugueses, o maior com 16.000 membros; Sindicato Democrático dos Enfermeiros do Portugal; Sindicato Independente dos 
Quadro 3. Resultados do estudo RN4cast Portugal, 2017-18.

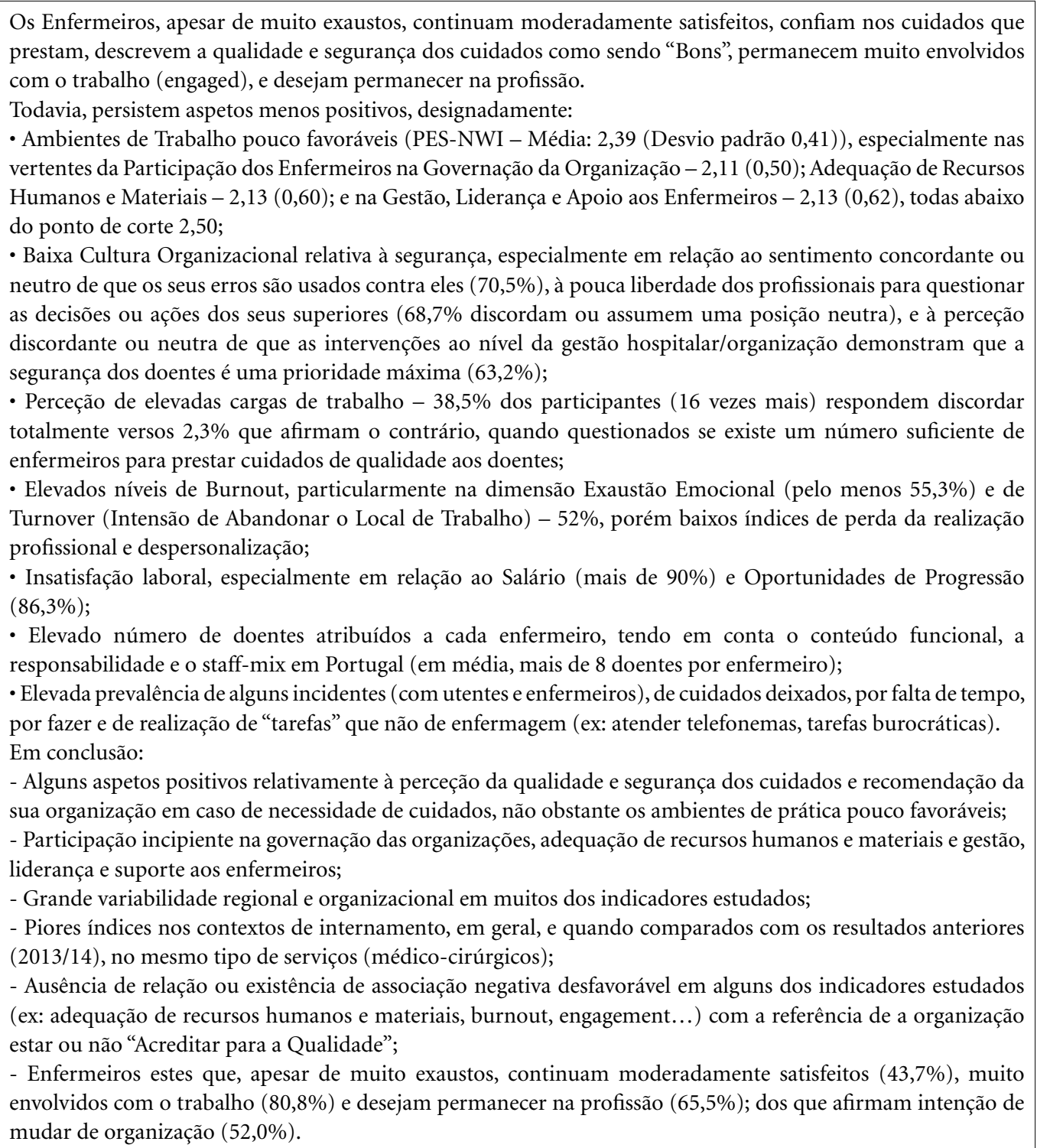

Fonte: Jesus ${ }^{24}$.

Profissionais de Enfermagem, Sindicato dos Enfermeiros da RA-SERAM) e associações de fins científicos (e.g. Associação Portuguesa dos Enfermeiros Gestores e Liderança), integradas de modo voluntário. A participação sindical dos enfermeiros, cuja percentagem exata não é conhecida, é muito fragmentada, o que gera algumas rivalidades. A Lei Sindical não inclui regras para a constituição de um sindicato, como um limiar de representatividade, e, só no ano 2018, surgiram 2 novos sindicatos, com revindicações mais fortes que as dos sindicatos mais tradicionais. Há um nível elevado de conflitualidade com o governo, acentuado pela falta de um quadro de regulamentação laboral pouco desenvolvido.

\section{Discussão e agenda para o futuro}

Nos últimos 40 anos, o número de enfermeiros formados quadruplicou, o que, à primeira vista, é um progresso substancial. Todavia, isto não foi suficiente para aumentar significativamente o rácio enfermeiro/médico, de 1.4, comparado 
ao rácio médio de 2.8 dos 35 países da OECD, e três vezes menor que o de países como Finlândia e Dinamarca ${ }^{25}$. Além de uma menor disponibilidade de enfermeiros, indica uma menor eficiência na produção dos serviços de saúde, particularmente nas USF, onde o número de médicos e de enfermeiros é praticamente semelhante. A divisão do trabalho entre médicos e enfermeiros mudou pouco ao longo dos anos, apesar dos esforços da Ordem e das associações profissionais com o progressivo reconhecimento quer de áreas de especialização quer de áreas de competências acrescidas, enquanto alguns dos cuidados prestados pelos médicos poderiam ser prestados por enfermeiros, com um impacto positivo sobre a produtividade das equipas ${ }^{2}$. As atividades formalmente realizadas pelos enfermeiros de cuidados gerais mudaram pouco ao longo dos anos, apesar dos enfermeiros, sobretudo especialistas ou detentores de certificação de competências acrescidas, possuírem conhecimentos e habilidades que permitem realizar atividades mais complexas de modo autónomo, como gerir pacientes crónicos estáveis, gravidez normais, prescrever algumas ajudas técnicas e alguns fármacos, análises e exames, sem qualquer risco para o utente.

Num grande número de países da OCDE, os enfermeiros têm vindo a assumir cuidados tradicionalmente da área de atuação de profissionais médicos, exercendo papéis novos e suplementares destes profissionais. Programas de formação tendo em vista a obtenção de novas competências estão disponíveis e quadros normativos e legislativos adaptados enquadram legalmente o exercício avançado de cuidados de enfermagem ${ }^{26}$. Em Portugal, a nível dos profissionais, há abertura para a expansão do papel do enfermeiro, mas há resistência por parte da Ordem dos Médicos e uma fraca capacidade de advocacia da profissão por conta de algumas divisões internas em torno desse assunto ${ }^{27,28}$.

O aumento do número de enfermeiros e enfermeiros especialistas, e simultaneamente a expansão do seu papel são desafios muito exigentes e permanentes. Primeiro, é preciso atrair mais pessoas para enfermagem, o que vários países europeus fizeram com um relativo sucesso através de estratégias como promoção da profissão nas escolas secundarias ou oferta de bolsas de estudo $^{29}$. Depois, há que reter o pessoal disponível, proporcionando ambientes de prática mais positivos, garantindo oportunidades de desenvolvimento profissional, melhorando as remunerações e oferecendo horários de trabalho mais flexíveis a enfermeiros com crianças pequenas ou idosos/adultos dependentes, prevenindo saídas prematuras pela oferta de condições de trabalho menos exigentes aos enfermeiros mais velhos. Tais medidas ajudariam a corrigir os aspetos negativos das condições de trabalho revelados pelo estudo RN4cast. A adoção de políticas de melhoria das condições de trabalho e de reconhecimento do papel dos enfermeiros pode contribuir para limitar a emigração, cujos custos são elevados dado o investimento consentido na formação dos que saem. Formar mais enfermeiros implica o fortalecimento da capacidade das instituições de formação, em particular pelo recrutamento de formadores qualificados; exige também a ampliação da rede de sítios de formação clinica. Por último, exige também, o compromisso, por parte dos principais empregadores, nomeadamente o sector público, em contratar efetivamente mais pessoal.

A redefinição do papel do enfermeiro é um desafio mais político que técnico que só pode acontecer se a própria profissão apresentar uma frente consensual e conseguir o apoio social e político necessário para a revisão da legislação relevante. Todavia, é necessário definir que enfermagem se pretende em Portugal - se mais generalista ou mais especializada, que modelo deve enquadrar a formação graduada e especializada destes profissionais e principalmente a que conceito se refere o enfermeiro especialista (e.g., nurse specialist vs advanced nurse practitioner). Esta clarificação é de suma importância já que as competências de um e de outro, assim como a abrangência das mesmas, são bastante diferentes, exigindo diferente planeamento e combinação de competências entre os diferentes elementos da equipa de saúde.

A exclusividade do ensino graduado da enfermagem a nível do ensino politécnico é, talvez, um dos grandes impedimentos ao desenvolvimento científico da profissão, já que não é possível desenvolver programas de doutoramento nestes institutos (apenas de mestrado), exactamente onde existe a grande maioria da reserva de conhecimento empírico da ontologia e epistemologia da profissão. A resolução deste problema também exige uma vontade política firme de aumentar a disponibilidade, a acessibilidade e a eficiência dos serviços de saúde e mobilização dos recursos políticos e financeiros necessários.

Em Portugal, as condições de trabalho no sector público, caracterizadas por salários baixos, cargas elevadas e poucas possibilidades de desenvolvimento profissional, mudaram pouco desde a criação do SNS. A situação dos outros 
profissionais de saúde é comparável à dos enfermeiros. Ainda falta uma politica abrangente de recursos humanos em saúde, um problema identificado há muito tempo ${ }^{14}$. Não há visão explícita do futuro do SNS e do sector da saúde em geral, nem existe um processo de planejamento sistemático dos recursos humanos. Um sistema de informação integrado, confiável, atualizado e de fácil acesso, permitiria caracterizar a força de trabalho do sector privado, monitorizar a mobilidade entre o SNS e o privado, as saídas do país e do próprio sector da saúde, e servir de material para produção de dados e conhecimentos validos sobre a força de trabalho em saúde. Em relação à enfermagem, um investimento na investigação é urgente para informar a definição de políticas que podem contribuir a utilização mais racional dos conhecimentos e das capacidades dos enfermeiros.

\section{Conclusão}

Paralelamente à criação e consolidação do SNS, a enfermagem assistiu, durante estes quarenta anos, a um desenvolvimento técnico e científico sem precedentes. Atualmente, a enfermagem é uma profissão altamente qualificada e relevante para a prestação de cuidados de saúde. Volvidos quarenta anos após a criação do SNS, torna-se essencial não só pensar uma nova estratégia de desenvolvimento e consolidação para as próximas décadas, mantendo o compromisso assumido com os cidadãos e visando um serviço capaz de responder às exigências demográficas, sociais e epidemiológicas que, entretanto, se alteraram; mas, também, repensar a enfermagem de forma a que continue a dar resposta às necessidades de saúde dos cidadãos e à crescente complexidade dos cuidados de saúde. Assim, a consolidação, reengenharia e desenvolvimento estratégico do SNS não podem ser desligados da análise das políticas de desenvolvimento dos recursos humanos da saúde, onde se enquadra o desenvolvimento da força de trabalho em enfermagem.

\section{Colaboradores}

G Dussault concebeu a estrutura inicial do manuscrito; I Fronteira e EH Jesus concordaram e contribuiram a todas as fases de produção do manuscrito.

\section{Referências}

1. Portugal. Lei no 56, de 15 de setembro de 1979. Serviço Nacional de Saúde. Diário da República; 1979.

2. Simoes JA, Augusto GF, Fronteira I, Hernandez-Quevedo C. Portugal: Health System Review. Health Syst Transit 2017; 19(2):1-184.

3. Ferreira PC, editor. A saúde e o Estado: o SNS aos 40 anos. Lisboa: Conselho Económico Social; 2018.

4. Björnberg A, Phang AY. Euro Health Consumer Index 2018 Report [relatório na Internet]. Marseillan: Health Consumer Powerhouse; 2019. [acessado 2019 Fev 27]. Disponível em: https://healthpowerhouse.com/media/ EHCI-2018/EHCI-2018-report.pdf

5. República Portuguesa. Constituição da República Portuguesa, de 2 de abril de 1976 [documento na Internet]. [acessado 2019 Fev 27]. Disponível em: https://www. parlamento.pt/parlamento/documents/crp1976.pdf

6. República Portuguesa. Decreto-lei ${ }^{\circ} 357$, de 6 de setembro de 1982. Concede ao Serviço Nacional de Saúde autonomia administrativa e financeira [documento na Internet]. Diário da República; 1982. [acessado $2019 \mathrm{Fev}$ 27]. Disponível em: https://dre.tretas.org/dre/19508/ decreto-lei-357-82-de-6-de-setembro 
7. República Portuguesa. Decreto-Lei $74-C$, de 2 de março de 1984. Cria, no âmbito do Ministério da Saúde, a Direção-Geral dos Cuidados de Saúde Primários [documento na Internet]. Diário da República; 1984. [acessado 2019 Fev 27]. Disponível em: https://dre.pt/ application/conteudo/405702

8. República Portuguesa. Despacho Normativo $n^{\circ} 97$, de 22 de abril de 1983. Aprova o Regulamento dos Centros de Saúde [documento na Internet]. Diário da República; 1983. [acessado 2019 Fev 27]. Disponível em: https:// dre.pt/application/conteudo/311838

9. Simões J, Fronteira I. Ciclos Políticos, em Portugal, e papel do Estado e dos setores privado e Social, na Saúde. e-Pública 2019; 6(1):4-14.

10. Ferrinho P, Simões J, Miguel JP, Beja A, Cortes M, Hartz Z. Da gestão estratégica do sistema de saúde português à avaliação do seu desempenho - um percurso em construção. IHMT 2013; 12: 76-87.

11. República Portuguesa. Lei no 48 , de 24 de agosto de 1990. Lei de Bases da Saúde [documento na Internet]. Diário da República; 1990. [acessado 2019 Fev 27]. Disponível em: https://dre.pt/application/conteudo/574127

12. Dussault G. Plano Nacional de Saúde 2012-2016 Roteiro de Intervenção Recursos Humanos em Saúde [documento na internet]. 2014 [acessado 2019 Nov 11]. Disponível em: http://1nj5ms2lli5hdggbe3mm7ms5. wpengine.netdna-cdn.com/files/2014/12/2014_13_Recursos-Humanos-Saude.pdf

13. República Portuguesa. Lei $\mathrm{n}^{\circ}$ 95, de 4 de setembro de 2019. Aprova a Lei de Bases da Saúde e revoga a Lei no 48/90, de 24 de agosto, e o Decreto-Lei n. ${ }^{\circ}$ 185/2002, de 20 de agosto [documento na internet]. Diário da República; 2019. [acessado 2019 Nov 11]. Disponível em: https://dre.pt/home/-/dre/124417108/details/maximized

14. Dussault G, Biscaia A, Craveiro I, Fronteira I, Lapão L, Temido M, Os Recursos Humanos da Saúde: uma agenda ainda para enfrentar [Human resources for health: na agenda still to be advanced]. In: Simões J, Correia Campos A. 40 anos de Abril na Saúde. Lisboa: Almedina Ed.; 2014. p. 163-183.

15. Ministério da Saúde. Serviço Nacional de Saúde: Evolução de Recursos Humanos no SNS entre 2015 e 2018 [Internet]. Lisboa: Ministério da Saúde; 2018. [acessado 2019 Fev 27]. Disponível em: https://www.sns.gov.pt/ noticias/2019/03/12/evolucao-dos-recursos-humanosno-sns-entre-2015-e-2018

16. Pereira C. A New Skilled Emigration Dynamic: Portuguese Nurses and Recruitment in the Southern European Periphery. In: Pereira C, Azevedo J, editoras. New and Old Routes of Portuguese Emigration: Uncertain Futures at the Periphery of Europe. Lisboa: Springer International Publishing; 2019. p. 97-121. (IMISCOE Research Series).

17. Biscaia A, Heleno LVC. A Reforma dos Cuidados de Saúde Primários em Portugal: portuguesa, moderna e inovadora. Cien Saude Colet 2017; 22(3):701-712.

18. Lapão LV, Pisco L. A reforma da atenção primária à saúde em Portugal, 2005-2018: o futuro e os desafios da maturidade. Cad Saude Publica 2019; 35(Supl. 2):e00042418.
19. Dussault G, Fronteira I. Recursos Humanos para a Saúde (RHS): Plano integrado no plano nacional de saúde 2011-16. Lisboa: Alto Comissariado da Saúde; 2010.

20. Craveiro I, Ferrinho P. Planear estrategicamente: a prática do SNS. Rev Port Saúde Pública 2001; 19(2):27-37.

21. Fronteira I, Conceição C, Biscaia A. Políticas de saúde e enfermagem em Portugal: perspectivas evolucionistas para um futuro incerto. In: Lima J, Pereira H, editores. Políticas públicas e conhecimento profissional: a educação e a enfermagem em reestruturação. Porto: Livpsic/Legis Editora; 2008.

22. República Portuguesa. Regulamento no 556, de 17 de outubro de 2017. Regulamento Geral das Áreas de Competência Acrescida. Diário da República; 2017.

23. República Portuguesa. Decreto-Lei no 247, de 22 de setembro de 2019. Regime da carreira de enfermagem nas entidades públicas empresariais e nas parcerias em saúde, bem como os respetivos requisitos de habilitação profissional e percurso de progressão profissional e de diferenciação técnico-científica [documento na internet]. Diário da República; 2019. [acessado 11 Nov 2019]. Disponível em: https://data. dre.pt/eli/dec-lei/247/2009/p/cons/20190527/pt/html

24. Jesus EH. Comunicação online dos principais resultados preliminares do inquérito RN4cast [página na Internet]. 2018 [acessado 2019 Fev 27]. Disponível em:https://www.facebook.com/rn4castportugal/ posts $/ 2225183454435829$ ?_tn__ $=\mathrm{K}-\mathrm{R}$

25. Organisation for Economic Co-operation and Development (OECD). Health at a Glance 2017: OECD Indicators. Paris: OECD Publishing; 2017.

26. Maier CB, Aiken LH, Busse R. Nurses in advanced roles in primary care: Policy levers for implementation. Paris: OECD Publishing; 2017.

27. Temido M, Craveiro I, Dussault G. Perceções de equipas de saúde familiar portuguesas sobre o alargamento do campo de exercício da enfermagem. Referência-Revista de Enfermagem 2015; IV(6):75-85.

28. Temido M, Dussault G. Papéis profissionais de médicos e enfermeiros em Portugal: limites normativos à mudança. Rev Portuguesa de Saúde Pública 2014; 32(1):45-54.

29. Kroezen M, Dussault G, Craveiro I, Dieleman M, Jansen C, Buchan J, Barriball L, Rafferty AM, Bremner J, Sermeus W. Recruitment and retention of health professionals across Europe: A literature review and multiple case study research. Health Policy 2015; 119(12):1517-1528.

Artigo apresentado em 13/04/2019

Aprovado em 20/08/2019

Versão final apresentada em 30/09/2019 